\title{
A criação da Empresa Brasileira de Serviços Hospitalares (EBSERH): um estudo de caso
}

The foundation of Brazilian Company of Hospital Services: a case study

La fundación de la Empresa Brasileña de Servicios Hospitalarios: un estudio de caso

Renata Machado dos Santos Gomes ${ }^{1}$

RESUMO: Este artigo, de abordagem qualitativa, constitui-se em um estudo de caso sobre a criação da Empresa Brasileira de Serviços Hospitalares (EBSERH). Com essa finalidade, o estudo descreve o processo e os instrumentos jurídicos que subsidiaram o debate para a estruturação da Empresa, destacando as dinâmicas políticas e sociais.

Palavras-chave: Reforma da Administração Pública. Hospitais Universitários. Empresa Pública.

ABSTRACT: This article, with a qualitative approach, is a case study on the creation of the Brazilian Company for Hospital Services (Empresa Brasileira de Serviços Hospitalares EBSERH). With this aim, the study describes the process and the legal instruments that aided and backed the debate to structure the Company, highlighting the political and social dynamics.

Keywords: Public Management Reforms. University Hospitals. Public Company.

RESUMEN: Este artículo, de abordaje cualitativo, constituye un caso sobre la creación de la Empresa Brasileña de Servicios Hospitalarios (EBSERH). Con este propósito, el estudio describe el proceso y los instrumentos jurídicos que han respaldado el debate para estructurar la Empresa, subrayando las dinámicas políticas y sociales.

Palabras-Ilave: Reforma de Gestión Pública. Hospitales Universitarios. Compañía Pública.

\section{Introdução}

A crise do Estado de Bem Estar Social, intensificada no fim da Segunda Grande Guerra, propiciou a disseminação de concepções neoliberais, sob a ideologia do Estado mínimo, especialmente na segunda metade do século $X X(1)$. No Brasil, a promulgação do Decreto-Lei no 200 (2), em 1967, pode ser considerada a primeira tentativa do governo de implementar esse novo conceito.

\footnotetext{
${ }^{1}$ Analista Técnico de Políticas Sociais. Corregedoria-Geral. Ministério da Saúde. Brasília - Distrito Federal. Brasil. E-mail: renatta.msgomes@gmail.com
} 
Esse decreto inaugurou o processo de reforma da administração burocrática central. Uma das novidades foi a possibilidade da administração indireta contar com as empresas públicas. Segundo o inciso II do Art. 5ํำ da referida norma legal (2), com a redação alterada pelo Decreto-Lei no 900/1969 (3), denomina-se empresa pública:

(...) a entidade dotada de personalidade jurídica de direito privado, com patrimônio próprio e capital exclusivo da União, criado por lei para a exploração de atividade econômica que o Governo seja levado a exercer por força de contingência ou de conveniência administrativa podendo revestir-se de qualquer das formas admitidas em direito. (2) (3)

No governo Collor, nasceu o Programa Nacional de Desestatização, intensificando a redução do poder do Estado e as privatizações, entre os anos de 1990 e 1992. A partir de 1995, o governo Fernando Henrique estabeleceu o Plano Diretor da Reforma do Aparelho do Estado, sob o comando de Bresser Pereira. A principal alegação para a mudança era a de que, diante da crise fiscal, uma administração rígida e burocrática atrasaria o desenvolvimento nacional. Em sendo assim, os serviços que não fossem de execução exclusiva do Estado, deveriam ser descentralizados ou, mesmo, privatizados (4).

$O$ resgate da autonomia financeira e da capacidade de implementar políticas públicas seriam desencadeados por uma ampla Reforma do Estado, mediante o modelo gerencial de gestão com a redefinição do papel do Estado (4). Todavia há uma distinção entre aparelho do Estado e Estado. O aparelho do Estado constitui-se na estrutura organizacional do Estado, tendo "(...) o poder de legislar e tributar a população de um determinado território" (4). O Estado é o sistema constitucional-legal, com a prerrogativa de promover e regular o desenvolvimento.

Assim:

(...) reforçar a governança - a capacidade de governo do Estado - através da transição programada de um tipo de administração pública burocrática, rígida e ineficiente, voltada para si própria e para o controle interno, para uma administração pública gerencial, flexível e eficiente, voltada para o atendimento do cidadão (4).

No modelo gerencial, o controle mantém-se nos resultados, uma diferença marcante em relação ao modelo de administração pública burocrática, cujo controle tem foco nos processos. Dessa forma, baseava-se na definição de objetivos claros, e na garantia de autonomia do administrador na gestão de pessoas, materiais e de recursos financeiros (4). 
No âmbito da saúde, essa perspectiva gerencialista começou a ser empreendida para tentar driblar a escassez de recursos humanos, materiais e financeiros pela qual passavam os hospitais universitários federais desde o final da década de 1980 (5). Essa situação foi agravada a partir da década de 1990, com Lei no 8.080/90 (6) que estabeleceu no art. 45 a integração dos serviços dos hospitais universitários e de ensino ao Sistema Único de Saúde por meio de convênio.

Essa instituição normativa inaugurou a transição de hospitais-escola com atendimento para os que não tinham carteira assinada para hospitais gerais vinculados ao Sistema Único de Saúde, com atendimento aberto a toda a população, embora a gestão permanecesse com o Ministério da Educação (MEC) (5).

Essa mudança instaurou uma cooperação associativa entre as áreas da educação e da saúde. Com o convênio, houve uma igualdade jurídica entre todos os signatários e ausência de vinculação contratual. Pietro (7) conceitua convênio como "(...) a forma de ajuste entre o Poder Público e entidades públicas ou privadas, para a realização de objetivos de interesse comum, mediante mútua colaboração”. Meirelles (8) argumenta que no convênio as partes têm interesses comuns e coincidentes, são partícipes com as mesmas pretensões.

A crise nesses hospitais intensificou-se nos anos 2000, levando o governo a iniciar uma série de discussões sobre o tema e a publicar, em 23 de maio de 2003, a Portaria Interministerial MS/MEC/MCT/MPOG nº 562/2003 (5), que criou uma comissão interinstitucional com representantes do Governo e da sociedade civil organizada. $O$ objetivo dessa Comissão era avaliar e diagnosticar a situação dos HUFs e de ensino no Brasil, com o intuito de reorientar e formular a Política Nacional para o setor (5).

Inseridos nesse contexto, o MEC e o Ministério da Saúde (MS) instituíram em parceria alguns programas, como forma de amenizar essa crise, a exemplo do Programa de Reestruturação dos Hospitais de Ensino do MEC no Sistema Único de Saúde (SUS) (9) e do Programa de Reestruturação dos Hospitais de Ensino no âmbito do SUS (10) (11).

$\mathrm{Na}$ sequência, instituíram o Programa Nacional de Reestruturação dos Hospitais Universitários Federais - REHUF, mediante o Decreto ํㅜ 7.082/2010 (12). Um programa de financiamento paritário entre as áreas da educação e da saúde. Uma resposta provisória à crise de gestão pela qual passavam os hospitais vinculados às Instituições Federais de Ensino Superior (IFES) (12) (5). 
O objetivo do Programa de Reestruturação, conforme descrito no caput do Art. $2^{\circ}$ Decreto $n^{\circ} 7.082 / 2010$ (12), era: “(...) criar condições materiais e institucionais para que os hospitais universitários federais pudessem desempenhar plenamente suas funções em relação às dimensões de ensino, pesquisa e extensão e à dimensão da assistência à saúde".

O referido diploma normativo (12) foi regulamentado pela Portaria Interministerial Ministério da Saúde e do Ministério da Educação ํㅛ 883, de 5 de julho de 2010 (13), que divulgava entre outros assuntos, a relação dos 46 hospitais universitários que fariam parte do REHUF.

Para trazer equilíbrio à atuação do MEC e do MS no REHUF, além da participação do Ministério do Planejamento, Orçamento e Gestão (MPOG), foi instituído o Comitê Gestor do REHUF, responsável por analisar e aprovar as ações propostas no âmbito do Programa (14).

A decisão da descentralização dos recursos caberia ao Comitê Gestor do REHUF, composto por representantes do Ministério da Educação (MEC); Ministério da Saúde - MS; Ministério do Planejamento, Orçamento e Gestão (MPOG); Associação Nacional dos Dirigentes das Instituições Federais de Ensino Superior (ANDIFES); Hospitais Universitários Federais (HUF); Conselho Nacional de Secretários Estaduais de Saúde (CONASS); e Conselho Nacional de Secretários Municipais de Saúde (CONASEMS) (12).

Entretanto, apesar da ampliação das fontes de financiamento para os hospitais universitários federais, a falta de profissionais devido a baixa regularidade de concursos públicos, induziu as universidades a contratar terceirizados, por meio de fundações de apoio (1).

Nessa ocasião, “(...) o governo começou a colocar em prática o que seria a sua mais recente tentativa de flexibilização do regime jurídico dos serviços de saúde do país: a Empresa Brasileira de Serviços Hospitalares (EBSERH) (...)", mediante a promulgação da Lei no 12.550/2011(14) (1).

A primeira atribuição delegada à EBSERH foi a contratação de pessoal, institucionalizando o processo e organizando a força de trabalho no âmbito dos hospitais universitários federais. Enquanto que o MS destinaria recursos para despesas correntes e de capital (12). 
A EBSERH atuaria no sentido de modernizar a gestão dos hospitais universitários federais, preservando e reforçando o papel estratégico desempenhado por essas unidades de centros de formação de profissionais e de assistência à saúde da população, no âmbito do SUS (14).

O evento de criação e estruturação da EBSERH são o foco desta narrativa, discutido à luz das dinâmicas políticas e sociais.

\section{Metodologia}

O estudo empreendido, de abordagem qualitativa, constituiu-se em um estudo de caso.

(...) os estudos de caso evidenciam ligações causais entre intervenções e situações da vida real; o contexto em que uma ação ou intervenção ocorreu ou ocorre; o rumo de um processo em curso e maneiras de interpretá-lo; o sentido e a relevância de algumas situações-chave nos resultados de uma intervenção (...). (15)

Os dados secundários utilizados na análise documental de foram obtidos nos sítios da EBSERH/MEC (http://www.ebserh.gov.br/) e da Câmara dos Deputados (http://www2.camara.leg.br/busca/?q=ebserh \&x=0\&y=0).

O levantamento da legislação e normativas infraconstitucionais foi realizado por meio do Sistema de Legislação de Saúde do Ministério da Saúde (Saúde Legiswww.saude.gov.br/saudelegis), do Sistema de Legislação Hospitalar da EBSERH (EBlegishttp://eblegis.datalegis.inf.br/action/ResenhaAction.php?acao=recuperarResenhaModulo\&c od_menu=999\&cod_modulo=60).

De modo complementar, o trabalho contou com revisão de literatura sobre o tema a partir de textos obtidos na base de dados Scielo ${ }^{2}$, no Google Academics ${ }^{3}$ e na Biblioteca Digital do Senado Federal ${ }^{4}$.

\footnotetext{
${ }^{2}$ http://search.scielo.org/

${ }^{3}$ https://scholar.google.com.br/scholar?hl=pt$\mathrm{BR} \& \mathrm{q}=$ empresa+brasileira+de+servi\%C3\%A7os+hospitalares\&btnG=\&lr= ${ }^{4}$ http://www2.senado.leg.br/bdsf/discover?query=ebserh\&submit=Ir\&filter_relational_operator_2=contains\&filte rtype_1=type\&filter_relational_operator_1=notequals\&filter_1=not\%C3\%ADDcia+de+jornal
} 


\section{Resultados e Discussão}

A aprovação da Medida Provisória no 520, de 31 de dezembro de 2010, pelo então Presidente Lula, foi a primeira iniciativa legislativa a favor da EBSERH. A Medida, promulgada no final do segundo mandato presidencial, autorizava a criação da EBSERH, definia as respectivas competências, o regime jurídico, a forma de administração, além da possibilidade de firmar contrato com instituições federais de ensino, entre outros assuntos.

Segundo o Relatório da Comissão Especial destinada a proferir parecer ao Projeto de Lei $n .01 .749$, de 2011, a medida foi o resultado da determinação do Acórdão $n^{\circ}$ 1.520/2006 - Plenário do Tribunal de Contas da União para a regularização da força de trabalho de vários órgãos públicos que empregam trabalhadores terceirizados em situação ilegal (17).

Nesse contexto, o Poder Executivo, visando oferecer uma solução para a questão da força de trabalho terceirizada dos hospitais universitários, propõe que seja autorizada a criação de empresa pública destinada a apoiar as atividades dos hospitais universitários, com o emprego de pessoal admitido por concurso público, em substituição aos terceirizados recrutados por meio das fundações de apoio às universidades. (17)

Conforme define Mendes (18), uma medida provisória nos termos da Constituição Federal de 1988 (19), possui “(...) índole normativa emergencial”. Desse modo, perde a eficácia desde a sua concepção caso não seja convertida em lei no prazo Constitucional (sessenta dias prorrogáveis por igual período), conforme o art. 62 da CF/1988 (19).

Em sendo assim:

(...) são pressupostos formais das medidas provisórias a urgência e a relevância da matéria sobre que versam (...), sendo que para que se legitime a edição da medida provisória, há de estar configurada uma situação em que a demora na produção da norma possa acarretar dano de difícil ou impossível reparação para o interesse público. (18)

Mendes (18) assevera, ainda, que a medida provisória produz dois efeitos básicos ao ser editada: "(...) inova a ordem jurídica imediatamente e provoca o Congresso Nacional a deliberar sobre o assunto".

Nesse aspecto, a MP № 520/2010 recebeu parecer favorável da Câmara dos Deputados, mas antes que fosse votada no Senado Federal teve a vigência expirada, extinguindo-se a eficácia da normativa (16). 
Por essa razão, em julho de 2011 foi apresentado à Câmara dos Deputados o Projeto de Lei o 1749 (PL o1749) (20). Neste o Poder Executivo solicitava a autorização do Legislativo para criar a EBSERH, entre outros assuntos.

Em Carta anexada ao Projeto (EM Interministerial no 00127/2011/MP/MEC, de junho de 2011), os Ministros da Educação e do Planejamento justificam a relevância e urgência da criação da EBSERH (20).

Com o argumento de uma solução jurídico-institucional sustentável, com base na estruturação de uma empresa pública, na solicitação (20) ressalta-se a finalidade pública das universidades, a vulnerabilidade dos hospitais universitários nesse contexto e declaram o desgaste do atual modelo jurídico de direito público:

4. A dupla finalidade pública - de assistência direta à população e de apoio ao ensino e à pesquisa das universidades - os diferenciam dos demais hospitais públicos e concede maior complexidade à sua gestão, que exige um nível de agilidade, flexibilidade e dinamismo incompatíveis com as limitações impostas pelo regime jurídico de direito público próprio da administração direta e das autarquias, especialmente no que se refere à contratação e à gestão da força de trabalho. A atual a força de trabalho dos hospitais universitários é composta por 70.373 (setenta mil, trezentos e setenta e três) profissionais, dos quais 26.556 (vinte e seis mil, quinhentos e cinquenta e seis) são recrutados por intermédio das fundações de apoio das universidades, sob diversos formatos legais: pelo regime celetista (CLT), por contratos de prestação de serviços (terceirização) e outros formatos que caracterizam vínculos precários sob a forma de terceirização irregular. 5 . Desde os anos 90, os hospitais universitários expandiram suas atividades sob bases institucionais frágeis e não sustentáveis em longo prazo, o que tem acarretado distorções, problemas cumulativos e vulnerabilidade jurídica. (20)

Na ocasião, a Presidente, mediante a Mensagem no 236 (21), recomendou urgência ao Congresso Nacional nas deliberações a respeito da aprovação da Lei de criação da EBSERH. E, na sequência, publicou o Ato da Presidência de 05/07/2011 criando a Comissão Especial destinada a proferir parecer sobre o referido PL (22).

Os três meses de análise da proposta, inicialmente pela Câmara dos Deputados, resultaram em alguns vetos e na Redação Final publicada e encaminhada ao Senado em 20 de setembro de 2011 (17) (23).

Dentre as nove emendas propostas estão a garantia da autonomia Constitucional dada as Universidades na administração de suas unidades hospitalares, com o veto do Art. $6^{\circ}$, $\S 3^{\circ}$, impedindo a administração, pela EBSERH, de unidades hospitalares integrantes 
de universidades federais, por constatação de inconstitucionalidade; o veto ao caput do Art. 3o, excluindo da redação do dispositivo a realização de atividades finalísticas, como a prestação de serviços gratuitos de assistência médico hospitalar, ambulatorial e de apoio diagnóstico e terapêutico à comunidade (17).

No Senado, o PL 1749/2011 (20), identificado como o Projeto de Lei da Câmara no 79, de 2011, foi aprovada pelo Plenário em 19 de dezembro de 2011 e transformado em norma jurídica, originando a Lei oํ 12.550/2011 (14).

De acordo com a Lei oㅜ 12.550/2011 (14), a finalidade da EBSERH era dar prosseguimento ao processo de recuperação dos hospitais universitários federais, passando a ser o órgão do MEC responsável pela gestão desse Programa de Reestruturação, por meio de contrato firmado com as universidades federais que assim optassem.

Sendo a adesão à EBSERH pelos Hospitais Universitários Federais voluntária, até 2014, 23 dos 49 HUFs já tinham firmado contrato com a Empresa, conforme descrito no relatório de uma Auditoria realizada pela Controladoria Geral da União (CGU) (24):

(...) verifica-se que a EBSERH é uma empresa pública que, devido a seu curto tempo de existência, está construindo sua estrutura organizacional e estabelecendo, desta forma, seu ambiente interno, apesar das lacunas existentes. No entanto, sua estrutura de controles internos, em fase de construção, está exposta aos riscos decorrentes de sua rápida expansão, pois até janeiro/2014 já tinha assumido o compromisso de gerir 23 hospitais universitários. (24)

Uma empresa pública, com personalidade jurídica de direito privado e patrimônio próprio (14). Pertence à administração indireta, vinculada ao Ministério da Educação, mas administrativamente e financeiramente autônoma (8).

Meirelles (8) explica que:

(...) o legislador procurou garantir a autonomia dessas entidades através de normas impeditivas de sua burocratização, de modo a lhes conceder ampla liberdade de ação na consecução de seus fins. Assim é que as considera vinculadas, e não subordinadas, aos respectivos Ministérios (...). (8)

Empresas públicas, conforme definiu Meirelles (8):

(...) pessoas jurídicas de Direito Privado, instituídas pelo Poder Público mediante autorização de lei específica, com capital exclusivamente público, 
para a prestação de serviço público ou a realização de atividade econômica de relevante interesse coletivo, nos moldes da iniciativa particular, podendo revestir qualquer forma de organização empresarial. (8)

Mello (25) acrescenta que empresa pública federal é criada por força de autorização legal como instrumento de ação do Estado, e que, embora tenha personalidade de Direito Privado, submete-se a certas regras especiais devido seu papel coadjuvante da ação governamental.

Nesse contexto, considera-se o debate sobre a criação de uma Empresa Pública para gerenciar os hospitais universitários federais e afins. Conforme March (26) a decisão do governo pela criação da EBSERH integra:

(...) as medidas adotadas desde o primeiro governo de Luiz Inácio Lula da Silva até o atual governo de Dilma Rousseff que operam a contrarreforma do Estado em sua dimensão administrativa e que guardam elementos de continuidade com o governo de Fernando Henrique Cardoso, em particular com o Plano Diretor da Reforma do Estado do então ministro de Estado Bresser Pereira (...). (26)

Vignoli Neto (1) afirma que o modelo administrativo sob o qual se fundamenta a EBSERH seria incompatível com "(...) o novo paradigma constitucional do Estado Democrático de Direito, que situa os serviços públicos sob o regime jurídico de direito público". Esse modelo, segundo Sodré et al (27), "(...) implica uma escolha legislativa pela relativização das normas de direito público, flexibilizando-as".

\section{Considerações Finais}

A Reforma da Administração Pública, institucionalizada e intensificada a partir do ano de 1995, baseou-se na perspectiva de flexibilizar algumas características do modelo burocrático, com foco nos resultados, sob o argumento da promoção de eficiência e da inovação administrativas.

Embora tenha sido fundada vinte anos depois, a EBSERH, com sede em Brasília, integra o conjunto desse processo. A concepção dessa Empresa Pública de Direito Privado envolveu uma mudança na prática de gestão, oportunizada pela crise dos hospitais universitários federais, principalmente devido às irregularidades constatadas pelo Tribunal de Contas da União na contratação de profissionais. 
Entretanto, o processo de implementação da Empresa nos territórios em que se localizam os hospitais universitários federais, deve considerar, a vocação para o ensino e a pesquisa dessas instituições, bem como a necessidade de saúde da região, estando sensível ao perfil demográfico e epidemiológico da população a ser assistida por esses serviços.

Por essa razão, as diretrizes do Sistema Único de Saúde, como universalidade, equidade, integralidade, e os respectivos princípios desse Sistema, a exemplo da participação do cidadão e da resolubilidade, são questões que devem ser resgatadas diante dos valores privados presentes no gerenciamento dos serviços públicos hospitalares pela EBSERH.

Ademais, ainda é cedo para afirmar as consequências da atuação da EBSERH. Nesse percurso, legitimidade e confiabilidade são critérios que devem ser perseguidos. Porque sendo a adesão à EBSERH voluntária, a imposição não seria uma opção diante da autonomia constitucional garantida pela Constituição às Universidades Públicas do país.

\section{Referências}

1 Vignoli Neto O. A flexibilização do regime jurídico de Direito Público na prestação de serviços públicos: estudo sobre a Empresa Brasileira de Serviços Hospitalares (EBSERH). Revista do CAA, 2013, XIX (1): 11-130. p.119

2 Brasil. Decreto-Lei 200, de 25 de fevereiro de 1967. Dispõe sobre a organização da Administração Federal, estabelece diretrizes para a Reforma Administrativa e dá outras providências. [Internet]. Brasília, 25 fev 1967 [Acesso em 12 dez 2015]. Disponível em: http://www.planalto.gov.br/ccivil_03/decreto-lei/Del0200.htm

3 Brasil. Decreto-Lei 900, de 29 de setembro de 1969. Altera disposições do Decreto-lei número 200, de 25 de fevereiro de 1967, e dá outras providências. [Internet]. Brasília, 29 set 1969 [Acesso em 12 dez 2015]. Disponível em:

http://www.planalto.gov.br/ccivil_03/decreto-lei/Del0900.htm

4. Brasil. Câmara da Reforma do Estado. Plano Diretor da Reforma do Aparelho do Estado. [Internet]. 1995 [Acesso em 26 dez 2015]. Disponível em:

http://www.bresserpereira.org.br/Documents/MARE/PlanoDiretor/planodiretor.pdf pp. 12; 13

5 Barros $R T$. Modelos de gestão na administração pública brasileira: reformas vivenciadas pelos hospitais universitários federais. RMP - Revista dos Mestrados Profissionais. Jan./jun. 2013 [Acesso em 24 ago 2015], 2 (1): 252-280. Disponível em: http://www.repositorios.ufpe.br/revistas/index.php/RMP/article/view/325 
6 Brasil. Lei no 8.080 , de 19 de setembro de 1990. Dispõe sobre as condições para a promoção, proteção e recuperação da saúde, a organização e o funcionamento dos serviços correspondentes e dá outras providências. Brasília, 19 set 1990 [Acesso em 15 ago 2015]. Disponível em: http://www.planalto.gov.br/ccivil_03/Leis/L8080.htm

\section{Pietro MSZD. Direito Administrativo. São Paulo: Editora Atlas S.A.; 2014.}

8 Meirelles HL, Aleixo DB, Burle Filho JE. Direito Administrativo Brasileiro. São Paulo: Malheiros Editores; 2015.

9 Brasil. Ministério da Saúde/Ministério da Educação. Portaria Interministerial no 1.006, de 27 de maio de 2004. Cria o Programa de Reestruturação dos Hospitais de Ensino do Ministério da Educação no Sistema Único de Saúde - SUS. Diário Oficial da União Brasília, 27 maio 2004 [Acesso em 01 nov 2015]. Disponível em: http://bvsms.saude.gov.br/bvs/saudelegis/gm/2004/anexo/anexo_pri1006_27_05_2004.pdf

10 Brasil. Ministério da Saúde. Gabinete do Ministro. Portaria no 1.702, de 17 de agosto de 2004. Cria o Programa de Reestruturação dos Hospitais de Ensino no âmbito do Sistema Único de Saúde - SUS, e dá outras providências. Diário Oficial da União. Brasília, 18 ago 2004 [Acesso em 01 nov 2015]. Disponível em: http://bvsms.saude.gov.br/bvs/saudelegis/gm/2004/prt1702_17_08_2004.html.

11 Martins VF. Hospitais universitários federais e a nova reestruturação organizacional: o primeiro olhar, uma análise de um hospital universitário. Revista de Administração e Contabilidade. Faculdade Anísio Teixeira, Feira de Santana, Bahia, 3 (2): 4-22, julho/dezembro, 2011.

12 Brasil. Decreto no 7.082, de 27 de janeiro de 2010. Institui o Programa Nacional de Reestruturação dos Hospitais Universitários Federais (REHUF). [Acesso em 24 ago 2015]. Disponível em: http://www.planalto.gov.br/ccivil_03/_Ato20072010/2010/Decreto/D7082.htm

13 Brasil. Ministério da Saúde/Ministério da Educação. Portaria Interministerial no 883, de 5 de julho de 2010. Regulamenta o Decreto no 7.082, de 27 de janeiro de 2010. Diário Oficial da União [Acesso em 24 ago 2015]. Disponível em:

http://www.ebserh.gov.br/documents/15796/65717/portaria_rehuf.pdf/43686833-d346489d-ab13-4a3a6b9cd075.

14 Brasil. Lei oㅜ 12.550, de 15 de dezembro de 2011. Autoriza o Poder Executivo a criar a empresa pública denominada Empresa Brasileira de Serviços Hospitalares - EBSERH. Brasília, 15 dez 2011 [Acesso em 26 ago 2015]. Disponível em: http://www.planalto.gov.br/ccivil_03/_ato2011-2014/2011/Lei/L12550.htm

15 Minayo MCS. O desafio do conhecimento: pesquisa qualitativa em saúde. São Paulo, Hucitec; 2008. 
16 Brasil. Senado. Medida Provisória ํㅡ 520 de 2011. Autoriza o Poder Executivo a criar a empresa pública denominada Empresa Brasileira de Serviços Hospitalares S.A. - EBSERH e dá outras providências. Brasília, 31 dez 2010 [Acesso em 26 ago 2015]. Disponível em: http://www010.dataprev.gov.br/sislex/paginas/45/2010/520.htm

17 Brasil. Câmara dos Deputados. Relatório da Comissão Especial responsável pela análise do Projeto de Lei 1749/2011. 2011 [Acesso em 27 dez 2015]. Disponível em: http://www.camara.gov.br/proposicoesWeb/fichadetramitacao?idProposicao $=511029$

18 Mendes GF, Branco PGG. Curso de Direito Constitucional. São Paulo: Saraiva; 2015. p. 914

19 Brasil. Presidência da República. Constituição Federal. 1988 [Acesso 20 ago 2015]. Disponível em: http://www.planalto.gov.br/ccivil_03/constituicao/constituicao.htm

20 Brasil. Câmara dos Deputados. Projeto de Lei nํ 1749, de 2011. 2011 [Acesso 20 dez 2015]. Disponível em:

http://www.camara.gov.br/proposicoesWeb/prop_mostrarintegra;jsessionid=F58ADD484EA 7B13BFB650FF922547C03. proposicoesWeb2?codteor $=895783 \&$ filename $=P L+1749 / 2011$

21 Brasil. Câmara dos Deputados. Mensagem Presidencial no 236 de 19 de julho de 2011 . [Acesso em 26 dez 2015]. Disponível em:

http://www.camara.gov.br/proposicoesWeb/prop_mostrarintegra;jsessionid=C4E516FB834 0A9B76AC2DA838CFC5836. proposicoesWeb2?codteor=895797\&filename=Tramitacao$\mathrm{PL}+1749 / 2011$

22 Brasil. Ato da Presidência de 05 de julho de 2011. [Internet]. [Acesso em 29 dez 2015]. Disponível em:

http://www.camara.gov.br/proposicoesWeb/prop_mostrarintegra;jsessionid=F58ADD484EA 7B13BFB650FF922547C03.proposicoesWeb2?codteor=896072\&filename=Tramitacao$P L+1749 / 2011$

23. Brasil. Câmara dos Deputados. 54ํㅡㄴ Legislatura - 1aㅗ Sessão Legislativa Ordinária. [Acesso em 29 dez 2015]. Disponível em:

http://www.camara.gov.br/internet/ordemdodia/ordemDetalheReuniaoPle.asp?codReuniao= 27040

24 Brasil. Controladoria Geral da União. Relatório de Auditoria Anual de Contas. Unidade Auditada: Empresa Brasileira de Serviços Hospitalares. Exercício 2013. Brasília, 26 set 2014: 10 [Acesso em 20 out 2015]. Disponível em:

http://sistemas2.cgu.gov.br/relats/uploads/RA201407932

25 Mello CAB. Curso de Direito Administrativo. São Paulo: Malheiros Editores; 2015.

26 March C. A Empresa Brasileira de Serviços Hospitalares, universidades públicas e autonomia: ampliação da subordinação à lógica do capital. DF, ano XXI , nำ49, janeiro de 
2012; p. 62. [Acesso em 20 out 2015]. Disponível em: http://apur.org.br/wpcontent/uploads/2013/09/imp-pub-1142951595.pdf

27 Sodré F, Littike D, Drago LMB, Perim MCM. Empresa Brasileira de Serviços Hospitalares: um Novo Modelo de Gestão? Serviço Social e Sociedade, abr/jun, 2013; 114: 365-380. 